\title{
LA CODIFICACIÓN DEL IMAGINARIO COTIDIANO: ESTEREOTIPOS Y LICENCIAS
}

\author{
THE ENCODING OF DAILY IMAGES: STEREOTYPES \\ AND GRAPHIC LICENCES
}

\author{
IGNACIO BARANDIARÁN \\ UPVIEHU \\ ignacio.barandiaran@ehu.eus
}

\begin{abstract}
Resumen: Este trabajo discute sobre realismo (fidelidad al modelo) y convención (estilización, ahorro y alteración de detalles) en las figuras humanas y animales del arte paleolítico. Se propone que estas licencias de la grafía prehistórica se corresponden con recursos retóricos del lenguaje hablado y escrito. En concreto, se pueden identificar casos de elipsis, sinécdoque, metonimia, hipérbole...

Palabras clave: Paleolítico superior, arte rupestre y mueble, licencias gráficas, realismo vs. Convención.

Abstract: This paper deals with the reality (fidelity to the model) and the conventionalisms (stylisation, economy and alteration of details) in the human and animal representations of Palaeolithic art. The main thesis is that these features of these prehistoric graphics are equivalent to rhetoric devices of spoken and written language such as ellipsis, synecdoche, metonymy, hyperbole, among others.

Keywords: Upper Palaeolithic, cave and portable art graphic licenses, realism vs. conventionalism.
\end{abstract}

Recibido: 15-03-2017

Informado: 01-04-2017

Definitivo: 17-04-2017

DOI: $10.1387 /$ veleia. 18072

\section{LAS VERSIONES GRÁFICAS DE LO COTIDIANO}

Los autores del arte paleolítico disponían de un banco de imágenes «tomadas de forma muy directa... del natural... de cuyo stock infinito se pudieron escoger a voluntad» (Clottes 1987, 43). En esa iconografía de lo cotidiano conviven figuras realistas (más fieles a sus modelos) y alteradas o francamente no identificables; los textos califican las primeras de correctas, de buen arte, completas, habituales o detallistas y las otras, a la contra, de raras, herméticas, incorrectas, parciales, esquematizadas, ilusorias o abstractas. Desde la premisa (García-Diez 2001, 116-117) de que todas las unidades gráficas «transmiten cierta cantidad de información... relativizada por el gusto estético y por otros intereses (que desconocemos) adoptados por el artista», se propone ordenarlas en gradación de «realismo, naturalismo, expresionismo, esquematización y estilización, desde la menor concentración y simplificación formal a la mayor, donde se reduce todo a simples líneas». 
Gustos, modas y creencias (como filtro cultural impuesto por el colectivo) acotarían iniciativa y habilidades del autor.

Advirtió H. Breuil $(1905,5)$ diferencias entre «el arte de las paredes que no presenta otras figuras estilizadas o simplificadas que las de los tectiformes y las manos, que degeneran en pectiformes y el arte mobiliar donde, al contrario, son numerosas las figuras alteradas, simplificadas o, como dice $S$. Reinach, estilizadas, en particular cabezas de caballos y de otros animales«. Razones de eficacia (ahorro de gestos) y expresivas (conseguir una simetría decorativa) habrían llevado a las gentes del Magdaleniense a la plasmación de figuras «degeneradas y estilizadas» en lo mobiliar (Breuil 1907, 394 y 402-403). Se reitera durante la primera mitad del siglo pasado (Breuil y Saint-Périer 1927 passim, Saint-Périer 1929, 43-55, Breuil y Lantier 1959, 214-215, etc.) ${ }^{1}$ que mucho grafismo descriptivo aboca en «no-real» (sea «decorativo», "geométrico» o «signo») afectando la transmutación a cabezas aisladas y a cuerpos vistos de frente (en cabras, caballos, bovinos y humanos), a cuerpos de costado (en bovinos, caballos, serpientes y peces) y a animales en fila (caballos y cérvidos).
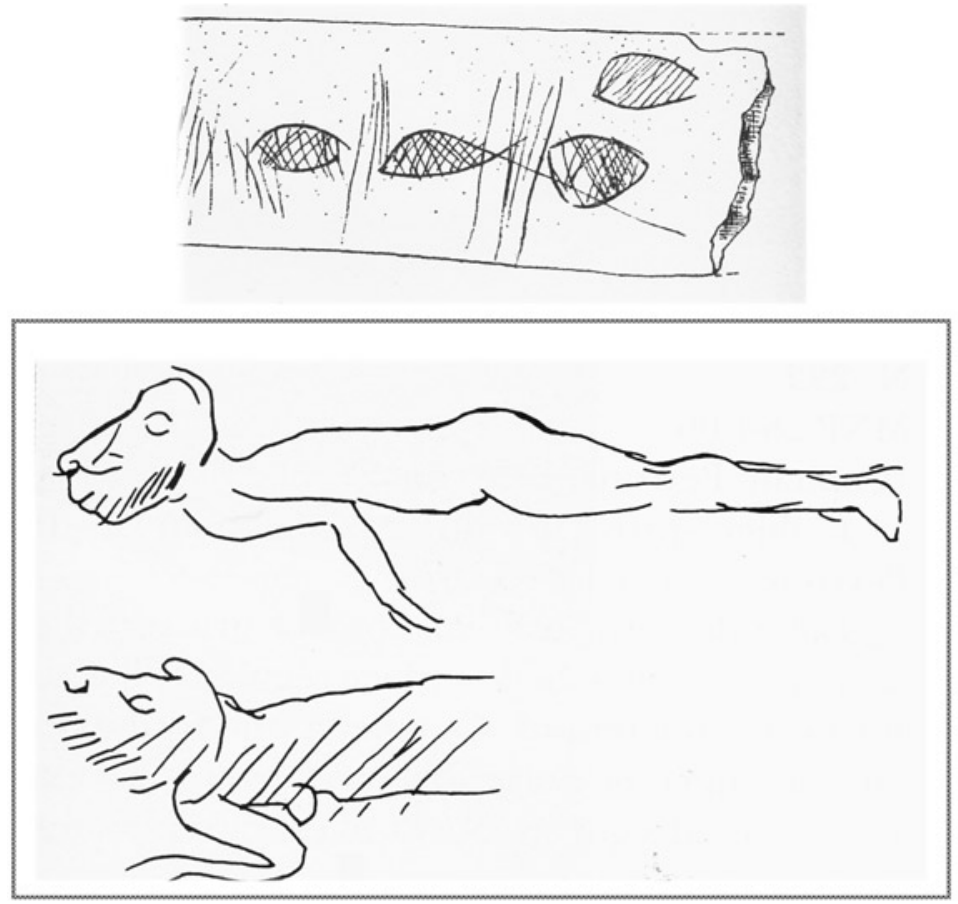

Figura i. Figuras esquematizadas de peces sobre una costilla de hueso de Altamira y de antropomorfos sobre un compresor de piedra de La Madeleine (Barandiarán M. 1972 b lám. 47.6; Tosello 2003 fig. 259a)

1 «El punto de partida de una verdadera estilización fue la figura animal de estilo naturalista, de cuya simplificación se originaron sencillos motivos de adorno, como pudo comprobarlo ingeniosamente $\mathrm{H}$. Breuil [asegurando que serían] dibujos por lo general esquemáticos y ligeros, pero no obstante artísticos... a no dudarlo, productos confeccionados a granel y por esto mismo degenerados» (Obermaier 1916, 218-220). 
R. Lantier $(1961,78-80)$ matiza esa evolución de lo real a su esquema y al signo con tres puntualizaciones: i, que se da de algún modo en todo el Paleolítico superior; ii, que todo es una peculiar versión del «realismo» («revelarían no un realismo visual, sino intelectual» de acuerdo con Luquet (1923 y 1926a); y iii, que lo decorativo puede originarse por un mecanismo formal (los conjuntos de imágenes reales, «muy simplificadas, reducidas a un cierto número de trazos reunidos, a veces «ornamentizados» se agrupan en decoraciones de aspecto geométrico») o técnico («derivado directamente de algunas técnicas... como las del trabajo del hueso [recorte, raspado, pulido, perforaciones etc.], de la cestería, del tejido, de la cordelería y de los objetos de adorno incluso... y hasta de la copia de algunos objetos como flechas más o menos estilizadas, arpones...»).

Se acepta alguna proximidad entre las versiones parietal y mobiliar de los grafemas. Y se reconocen como sus divergencias, entre otras: $i$, que acaso no fueran exactamente contemporáneas si una misma cueva servía de modo alternativo (Breuil 1963, 55) como «santuario» (con su efectivo rupestre) y como «habitación» (con el correspondiente efectivo portátil); ii, que no parecen similares las combinaciones de imágenes, pues «los artistas paleolíticos se dedicaron a la creación de «escenas» más a menudo y con resultados más satisfactorios en el efectivo mobiliar que en el rupestre» (Graziosi 1956, 28); y iii, que hay temas propios del imaginario «de cuevas y del de plaquetas y estatuillas... como las muy numerosas figuras esquemáticas geometrizadas a punto de pasar a ser verdaderas claves decorativas» (Leroi-Gourhan 1971, 125).

El Diccionario de la Lengua (uso su vigésimoprimera edición, de 1992) define: realidad/realismo como «imitación fiel de la naturaleza... contraposición con lo fantástico e ilusorio»; convención/convencionalismo como «norma o práctica admitida tácitamente, que responde a precedentes o a la costumbre»... «conjunto de procedimientos basados en ideas falsas que, por comodidad o conveniencia social, se tienen como verdaderas»; y código/codificación como «acción y efecto de aplicar... un sistema de signos y de reglas que permite formular y comprender un mensaje».

Según un lúcido resumen de la cuestión (Sauvet 1990, 96) «todo mensaje visual, como cualquier signo, posee contenido y forma. El contenido (o tema) puede pertenecer al mundo natural o ser una abstracción, igual que la forma puede ser naturalista o abstracta, o sea geométrica. El paso de una forma naturalista a una abstracta puede realizarse en continuo por simplificación o abreviatura de los contornos, por reducción a los trazos esenciales y abandono de los detalles, según un proceso de esquematización».

En este texto recordaré sólo las licencias de las unidades gráficas que tientan la representación del imaginario cotidiano animado: o sea, los individuos animales y humanos. Intencionadamente no se aborda ahora, por extenso, el listado y discusión de los recursos aplicados a grupos de figuras homoespecíficas que parecen integradas en escena ${ }^{2}$.

\section{Los CASOS}

La Preceptiva del Lenguaje (escrito y hablado) lista muchas figuras de construcción y de expresión, como licencias (elipsis, hipérbole, síncopa, sinécdoque, metonimia, retruécano...), metáforas o alegorías. Sin duda se pueden identificar con varios de los esterotipos y convenciones que simplifican o alteran los modelos cotidianos de la iconografía rupestre y mobiliar del Paleolítico superior.

2 Como, entre tantos, el «recubrimiento reservado» (Leroi-Gourhan 1975, 283) y la «represen- tación compartida» (Barandiarán y Laplace 2000, 25-27). 
Los términos «plantilla», "código», «fórmula» «sistema», «recurso» o "esquema», usuales en los textos sobre grafemas paleolíticos, parecen corresponderse con lo que se define como estereotipo ("gesto, fórmula, expresión, etc., que se repite sin variación» según el Diccionario) en el lenguaje oral y escrito. Desde la presunción de alguna alternancia o complementariedad entre "lo real» y «lo convencional» en ese arte, recogí (Barandiarán M. 1972a) como convenciones algunos recursos que servirían para expresar color y volumen/sombreado de figuras monocromas y características fanerópticas de algunas especies.

2.1. El trazado de la línea cérvico-dorsal sirve de plantilla (esquema morfosomático) de las figuras de équidos, bovinos, cérvidos, cápridos, mamuts etc. Sin confirmación analítica decisiva, se piensa que la silueta cérvico-dorsal se traza en seguido de delante atrás: de lo alto de la cabeza hasta el fin de la curvatura lumbar. El estudio de surcos de figuras de mamuts grabadas sobre la roca blanda de Rouffignac percibe (Barrière 1970) muchas excepciones a la supuesta norma: la silueta trompa+cabeza+línea cérvicodorsal se traza no seguida, sino interrumpida en tramos, y con direcciones opuestas (de delante atrás o de detrás adelante) o coincidentes.

«Cual sea el tema de las representaciones, hay una voluntad de destacar el contorno que identifica cada dibujo, sobre el que se irán agregando los elementos complementarios... con un orden de ejecución idéntica: [primero] los contornos identificativos... de adelante hacia atrás...; y, tras esos contornos que determinan la forma general, los atributos internos» (Fritz 1999, 202). El protocolo se aplica a la forma completa del animal, en la secuencia temporal del delineado cérvico-dorsal, cabeza, pata delantera, línea ventral, pata trasera y «lo complementario» (defensas, astas, trompa, partes internas de la cara y cuerpo, flancos, flecos de cola, orejas etc.). El análisis de las partes de los cuerpos sobre piezas mobiliares (Barandiarán M. 1984b; Fritz 1998) aprecia constantes en el cursus del trazado: de nuca a cola, la línea cérvico-dorsal de arriba abajo y de delante atrás, las patas y zona ventral; desde el arranque a la punta, los cuernos de cabra ${ }^{3}$.

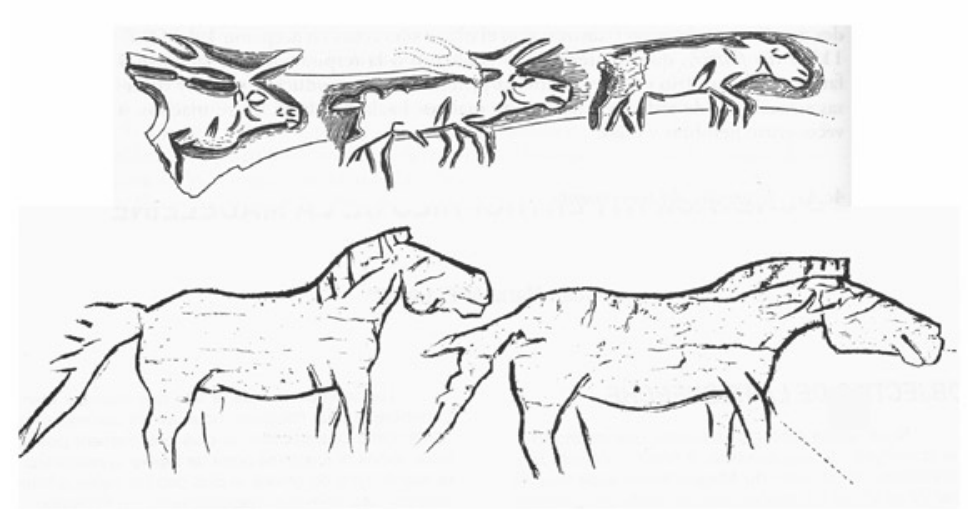

Figura 2. Animales de cabeza hipertrofiada: reno (el animal central de la serie) y caballos sobre bastones de asta de Limeuil y La Madeleine (Breuil en Capitan et alii 1910 fig. 168; Apellániz 1990 fig. 3.2)

3 A la contra, en la muestra de grabados parietales de Rouffignac se utilizan (Barrière 1970) otras fórmulas: los cuernos de bisonte y de rinoceronte se tra- zan desde la punta hacia su arranque; las defensas de mamut tanto desde la raíz hacia la punta como al revés. 
2.2. Mediante código o fórmula se aluden detalles definidores del bestiario: tachones o cortos trazos agrupados (a menudo a pares) o zigzas o líneas laterales sobre bóvidos y cérvidos, moteados o listados en crías de ungulados, series de tracitos cortos para marcar diferencias del pelaje de la cara de mamíferos (p.e. en el expresivo paradigma de cabezas de ciervos en sendos bastones de Valle y Pendo y de caballo, sarrio y uro en un tubo óseo de Torre (Obermaier 1932, figs. 3 y 4; Barandiarán M. 1971) y del plumaje de aves, o líneas paralelas y cruzadas aludiendo a escamas de peces.

2.3. En representaciones de peces y de cabras en posición frontal hay muchos ejemplos de esquema o estilización, de simplificación del grafema. En peces (Breuil y Saint-Périer 1927, 77-82, 132-140) se reconocen «desde» los que ofrecen su determinación específica (con detalles de silueta corporal, cabeza y aletas, coloración/disposición de escamas, etc) «hasta» las «inspiradas en la forma general del animal o en sus partes aisladas» y a los que "finalmente» dan en formas ahusadas, pares de arcos afrontados o trazos curvados... que, en ocasiones, sólo retienen del tema la línea que recorre el costado del animal. Hemos comentado con detalle (Barandiarán M. et alii 2013) los grafemas de cabras figuradas en posición frontal: «desde» su versión realista «a» la más esquematizada (cuestión recurrente a lo largo de un siglo de bibliografía desde Breuil 1907, 398-399 y figs. 3.6 a 3.26 a Azéma 2010, 187-218).

También se esquematizan frecuentemente "antropomorfos», con cabezas desfiguradas (o apenas detalladas) y cuerpos muy simplificados: caso de una figura masculina y otra femenina sobre sendas caras de un canto de piedra reutilizado como compresor de La Madeleine (Capitan y Peyrony 1928 , figs. 30.3 y 30.4$)$.

Entre los esquemas de figuras femeninas destacan las numerosas (algo más de 400) sobre placas de esquisto de Gönnersdorf, similares (Bosinski y Schiller 1998; Bosinski et alii 2001, 299-346) a algunas del repertorio parietal de Combarelles, Fronsac, Planchard... y portátil de Andernach, Hohlenstein, Gare de Couze, Saint-Antonin y colección de Roche/Lalinde. Y entre las masculinas (Haensch 1968) las de Cougnac, Pech-Merle, Combarelles, Mas d'Azil, Altamira u Hornos de la Peña en lo parietal y Madeleine, Isturitz, Montastruc/Bruniquel, Gourdan o Limeuil en lo mobiliar. Algunas figuras masculinas simplificadas se combinan con animales más realistas, como en varias supuestas escenas de caza del bisonte: en una placa de Laugerie-Basse, una bramadera de Raymonden/Chancelade) y un trozo de costilla de Château/Les Eyzies y en el parietal del pozo de Lascaux (Mortillet y Mortillet 1881, 203; Capitan et alii 1924, fig. 102; Luquet 1926a, 113 abajo; Graziosi 1956, lám. 283b).

Se ha discutido si algunos iconos excesivamente esquematizados aluden a humanos, como el colgante en marfil de Dolní Vestonice interpretado (Absolon 1949, 297) como «bizarra hiperestilizada, esteatomérica, pars pro toto de una estatuilla de venus». Al comparar bastones del Valle y del Pendo con figuras de cabezas sueltas muy detalladas (de cierva en el primer caso; de dos ciervas, un ciervo y un caballo en el segundo) Obermaier (1932, 12 y figs. 3-4) interpretó de modo distinto las unidades gráficas de menor tamaño presentes ante los hocicos de aquellos animales: en Valle, son cinco esquemas que «seguramente representan figuras humanas», y en Pendo, los cinco signos en aspa que "pertenecen al grupo de las llamadas «marcas de caza»». Se han rechazado las propues-

4 Algún prehistoriador que me leyó con reticencia ha de aceptarlo si atiende su definición en el Diccionario de la R.A.E.: despiece (o despiezo) es la acción y el re- sultado de despiezar (o despezar): «dividir las distintas partes que componen una obra». 
tas como «venus del Pendo» (que es sólo un colgante en asta) y «venus de Las Caldas» (figura de cabra de frente en semirrelieve sobre un propulsor).

En el parietal de Castillo se presentaron (Alcalde et alii 1911, 192 y figs. 196-197) cinco "pequeños signos negros (¿«muńecos esquemáticos»?)» y tres rojos similares "con aspecto de un esquema de figura humana». Hay cierto consenso, sin fuerza argumental que lo asegure o niegue, en acoger su extemporáneo estilo en el repertorio antropomórfico habitual del Paleolítico superior (Ripoll 1964, 96).

2.4. Apliqué el término despiece ${ }^{4}$ a la descomposición de la figura lateral de un cuerpo en planos (cubiertos por pigmento uniforme o por una masa de trazos grabados) o mediante líneas que la parcelan. Pueden servir (Barandiarán M. 1972a, 358-376) para expresar el volumen del cuerpo, distinguir sus partes, caracterizar coloración y estructura de pieles, etc. Cuatro de los bisontes pintados en negro y muy próximos en el reducido espacio de la "cámara» de Santimamiñe (Aranzadi et alii 1925, fig. 21) ofrecen ejemplo de varios de esos tratamientos. Entre bastantes otras figuras con despieces frecuentes destacan las de caballos, ciervas y peces.

Con grabado estriado se rellenan partes de la cabeza y cuello de figuras de ciervas (y algún otro animal). La fórmula se reconoció en placas de hueso halladas en las excavaciones de Altamira (en 1904) y Castillo (entre 1910 y 1914) en niveles del Magdaleniense inferior y en grabados sobre las paredes de ambos sitios. El mismo recurso en mobiliar y en rupestre se ha identificado posteriormente en unos cuantos sitios más del norte de la Península (Alonso Silió 1988; González Sáinz 1992), desde Peña de Candamo en Asturias a Alkerdi al norte de Navarra.

Las figuras de caballos (en numerosos grabados muebles y en los conjuntos de pintura rupestre de Le Portel, Niaux o Ekain) acumulan la mayor variedad de despieces. Propuse catorce tipos distintos de la fórmula (Barandiarán M. 1972 a, 358-366 y fig. 30 sobre los caballos de Ekain en Barandiarán M. 1974 ), según su forma y la zona del cuerpo que delimitan: cara, cuello, crines, mancha escapular, cebraduras de cuello+espalda y de patas, despieces laterales en M, etc. Parecen referir características de lo despiezado, en color, zonas sombreadas y volúmenes, calidades del pelaje (como, según observaciones del zoólogo Mázak 1961, matices del manto en su muda) etc.

2.5. Se escribe que cuando en el espacio de una plaqueta o de la zona reservada de un friso parietal no cabe la figura completa prevista, se le eliminan o reducen partes o simplifican detalles. Esta elipsis («omisión o distorsión de parte de una expresión y que no se precisa para la comprensión razonable del tema» en el Diccionario) afecta sobre todo a lo que sobresale de la masa del cuerpo hacia arriba (cuernos y astas), hacia adelante (el conjunto de la cabeza, el prognatismo del hocico, las defensas o la trompa de un mamut...) y hacia abajo (las patas).

Un canto de Montastruc/Bruniquel (Sieveking 1987, lám. 100) acoge figuras realistas de un caballo y dos sarrios y una deformada de un sarrio (cabeza demasiado pequeña y patas replegadas) ocupando todas al completo el espacio disponible del soporte. Sobre un colgante en hueso de Mas d'Azil (Pales y Tassin de Saint-Péreuse 1981, 129) se grabaron cabras: correctas cabezas perpendiculares al eje del soporte en una cara y el cuerpo de otra con el cuerno dispuesto a lo largo y no hacia arriba (¿porque no cabe?) a lo largo de la cara opuesta. Otros casos de elipsis se dan en: las patas deformadas, reducidas de tamaño y esquematizadas del ciervo grabado sobre un bastón del Castillo y las de caballo, rebeco y vaca muy realistas del tubo de Torre (Breuil y Obermaier 1913, fig. 2; Barandiarán M. 1971); las patas cortas de una cabra sobre una gran laja de Chaleux (que la hacen para Twiesselmann 1951 lám. IX «cabra acostada»); las patas plegadas (menores de tamaño y deformes al plegarse bajo el vientre) en renos realistas sobre placas areniscas de Isturitz (Passemard 
1944, 54 y lám. 30); las patas traseras omitidas/plegadas anormalmente en el reno grabado en un recoveco de la cueva de Altxerri (Barandiarán A. 1964, 100); la trompa y las defensas hacia adelante en un mamut adaptado a la forma alargada de un propulsor de Montastruc/Bruniquel (Bahn y Vertut 1988, fig. 18); las astas de ciervos (sendos sobre bastones de Castillo y Cualventi) que se acortan o distorsionan hacia adelante (figuras de los bastones de Castillo y Breuil y Obermaier 1913, fig. 2; García Guinea 1988) etc.

2.6. Utilizan la sinécdoque (que «extiende, restringe o altera... una expresión gráfica... figurando un todo a través de una de sus partes») tantas imágenes paleolíticas incompletas (Mons 1990, 73): «órganos aislados» $\mathrm{y}$ "fragmentos del cuerpo» (vulvas, falos, ojos, manos, patas, cascos/pezuñas, astas, cabezas, protomos, cuartos traseros etc), «animales acéfalos», «figuras superpuestas» ${ }^{5}$ y "figuras de contorno discontínuo». Aduzco tres casos de caballos incompletos: la plaquita de piedra de Puits/Chaffaud con «una masa de caballos [treinta y dos] alineados uno junto al otro galopando a toda velocidad, [organizados en dos filas precedidos cada uno de ellos por un caballo destacado de cuerpo completo] siendo los demás solamente representados por la cabeza, el cuello y las patas anteriores» (Capitan et alii 1908, 214); la escultura que remata el extremo proximal de una lezna de asta de ciervo de Bolinkoba «cuya base acanalada... mango... semejaría una pata de caballo» (Barandiarán A. 1950, 98 y 103); y las figuras acéfalas del parietal de Monedas, Castillo, Portel, Bédeilhac o Combarelles (Ripoll 1972, 56-60).

2.7. Hay imágenes de animales en acción sin que se haya expresado la causa que la determina (Sauvet 1990, 95), al modo de lo que en preceptiva literaria es metonimia: «designar una cosa con el nombre de otra... tomando el efecto por la causa o viceversa, el autor por su obra, el signo por la cosa significada». En el grafismo paleolítico no se representan las condiciones o eventos ambientales (causa) que provocan actitudes (efecto) derivadas en las figuras representadas. Así ocurre en animales retrospicientes (Lombo et alii 2014) o en los que marchan o encaran un accidente del soporte sea la roca de la cueva o una placa de piedra o de hueso. Aunque casi nunca se han dibujado masas de agua ${ }^{6}$ se reconoce que han de interpretarse como grupos de animales que las cruzan los ciervos en estampida que parecen atravesar el agua donde nadan y evolucionan varios salmones en un bastón de Lortet o los cinco ciervos con sus cabezas alzadas en actitud de paso por una corriente en el parietal de Lascaux (Piette 1894, fig. 58; Graziosi 1956, lám. 194a). Se aventuró (Saint-Périer 1936, 84-86) que largas líneas onduladas grabadas sobre varillas de asta de Isturitz fueran plantas acuáticas agitadas por una corriente de agua (que, obviamente, no se figura).

Algunos han propuesto que figuras de herbívoros de cabeza agachada y al paso o parados estarían pastando, ramoneando o bebiendo sin que se hayan dibujado los correspondientes pastos, arbustos o aguas. Habitual la omisión de líneas que marquen las del firme que se pisa, se asumen como representaciones de animales en marcha, acostados, topándose o revolcándose sobre suelos gráficamente inexistentes. La causa/efecto de animal/movimiento se expresa en lo grabado sobre una placa de marfil de Malta con serpientes (Abramova 1967, 56-57): las figuras bastante fieles de tres de ellas en una de sus caras y motivos de puntuaciones y pequeñas cúpulas en espiral en la otra «cuya forma reproduce bien el movimiento de las serpientes... otorgándole muy posiblemente a la placa un significado mágico». La trama geométrica grabada sobre un hueso frontonasal de caballo

5 Donde alguna/s representación/es incompleta/s aprovecha/n lo ya figurado en la/s correspondiente/s completa/s.
${ }^{6}$ Salvo en los escasos mapas del arte mobiliar donde se han interpretado imágenes de cursos de ríos concretos (Barandiarán, M. 2006, 177). 

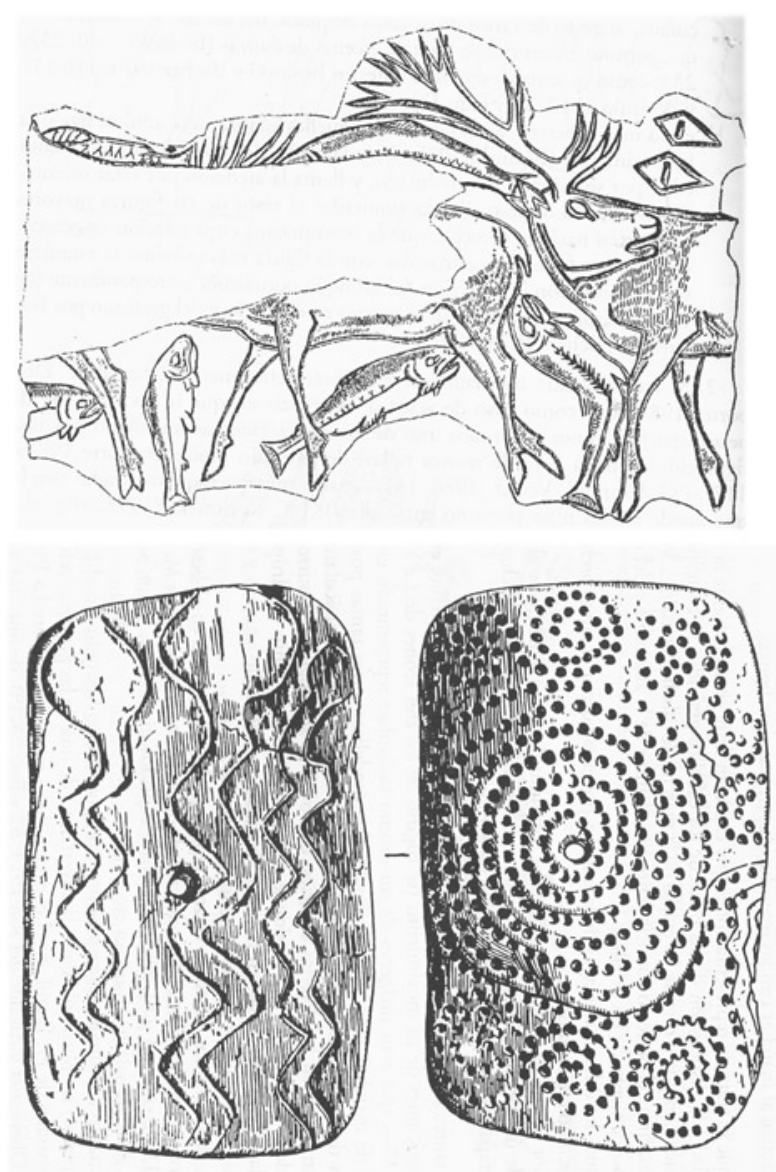

FIgURA 3. Ciervos en actitud de atravesar una corriente de agua en un bastón perforado de asta de Lortet y serpientes y esquema de su movimiento en sendas caras de una placalcolgante de marfil de Malta (Piette 1894 fig. 58; Abramova 1967 lám. L.2)

de Kendricks Cave (Sieveking 1972, 386) ¿asume en metonimia revertida («el signo por la cosa significada») la probable referencia esquematizada al pelaje de la cara del animal trazado precisamente sobre el correspondiente hueso de uno de ellos?

2.8. La hipérbole, como desproporción/desmesura de alguna parte de la figura ha sido bien diagnosticada en la hipertrofia de nalgas en caballos pintados en Ekain y en las 33 cabezas hipertrofiadas de caballos grabados sobre soportes de asta de sitios magdalenienses de Dordońa (Altuna y Apellániz 1978; Apellániz 1990, en hechura propia de una «escuela de La Madeleine»).

2.9. Se toman por caricaturas de humanos (Lombo 2014 y 2015) bastantes tropos inverosímiles del arte parietal y mueble (cuyos autores simplificaron, omitieron o exageraron rasgos físicos o de comportamiento): grotescos, extravagantes, bromas, retruécanos, imágenes de doble sentido, híbri- 
dos, máscaras, fantasmas calembours (término asumido de Luquet 1926a, 156), etc. Como híbridos destacan: en la mezcla humano/animal, los tres «diablejos», danzantes disfrazados o chamanes ${ }^{7}$ que acompañan varias figuras heterogéneas en un bastón de Mège/Teyjat (Capitan et al. 1909, figs. 4-5 y 11) y en la compuesta con partes de animales distintos, el "unicornio» (con detalles de, al menos, cuatro especies distintas) pintado en Lascaux, la cabra con alusión a astas de ciervo pintada en Niaux o el salmón «retrazado en atún» pintado/grabado en Pindal (Graziosi 1956, lám. 180b; Schmidt 1964; González-Pumariega 2013).
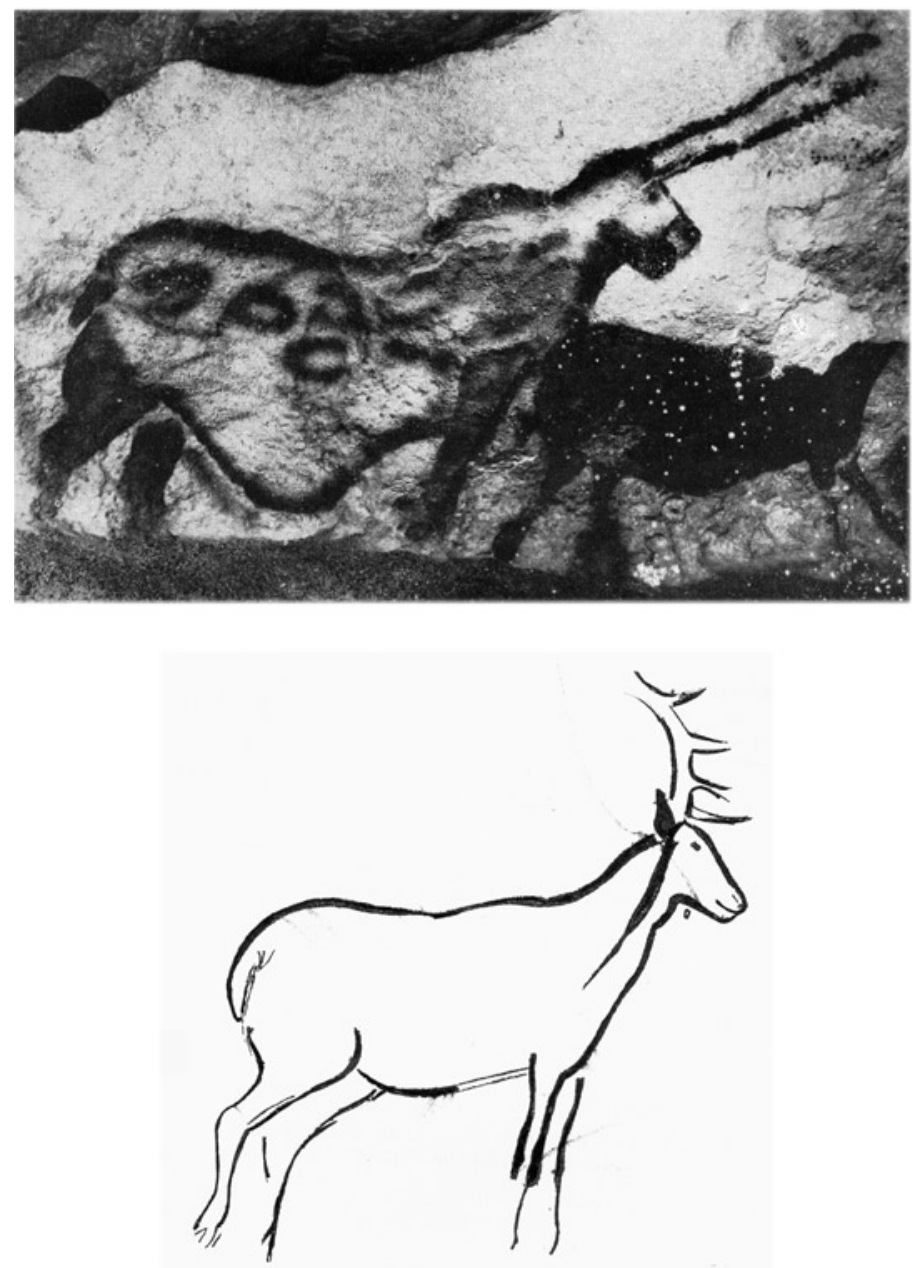

Figura 4. Hibridos de animales del parietal de Lascaux ("el unicornio») y de Niaux (cabralciervo) de Niaux (fotografia en Zervos 1959 y calco de Breuil 1952)

\footnotetext{
7 «Sujetos imaginarios,... duendecillos o cocos (loups-garous)»(Reinach 1913, 181); «diablejos... personajes enmascarados y disfrazados o espíritus (Capitan et alii 1924, 114); "figuras de piernas humanas, cuerpo peludo y cabeza de rebeco» (Breuil y Lantier 1959, 212);
}

"chamanes danzantes de piernas desnudas, con vestido y máscara de rebeco» (Marshack 1972, 260); «jóvenes danzantes disfrazados de rebeco» (Leonardi 1987, 189); «diablejos» (Duhard 1996, 116-119); etc. 
2.10. Se coincide en asegurar que muchas unidades gráficas del signario pueden ser fórmulas de abstracción de lo cotidiano. Frente al «mundo exterior» (Jordá 1964, 15-17: «zoomorfos, según moldes de representación realista con ciertos convencionalismos» $\mathrm{y}$ "antropomorfos, representaciones idealizadas de hembras y varones reales») están los signos referentes de un «mundo interior» («los ideomorfos desprovistos de todo punto de contacto con la realidad, elementos ideales, puras abstracciones... tipos de representación concreta y específica realizada more geometrico»). Los signos que «sorprenden por su carácter resueltamente abstracto... son mucho más numerosos y más variados que las representaciones zoomorfas» (Groenen 2000, 40).

Son distintos los signos rupestres y los mobiliares. En el repertorio rupestre (tectiformes, claviformes, cuadrillajes, series de puntos...) se figuran aislados (solos o en grupos) o asociados sobre o al lado de temas animales. Muchos de los signos trazados sobre el utillaje en hueso o asta se adaptan a su formato.

Algunos tipos de signos se centran en regiones y épocas, otros parecen más ecuménicos. En lo parietal se reconocen tectiformes tipo Monte Castillo (en Castillo, Pasiega y Chimeneas, más Altamira), escutiformes tipo Lascaux o claviformes y puntaciones más generalizados; en lo mobiliar, las «marcas de caza» del Gravetiense, los trazos pareados del Solutrense, etc.

Son muchos los intentos de reconocer el significado del signario (expuestos y contrastados en Leroi-Gourhan 1958a y 1958b; Casado 1977; Chollot 1980; Sauvet et alii 1979; Sauvet 1990 y 1993a; Groenen 2000, 40-46; Robert 2006, Mingo 2010 etc.). Entre tantas opiniones discutibles pueden recordarse desde las de Piette y otros de su tiempo proponiendo que algunos signos fueran inscripciones o firmas/marcas de sus autores, a la defensa por comparatistas etnográficos de que pueden representar (los tectiformes, claviformes, trazos de destrucción, penniformes, escutiformes, aviformes, serpentiformes,...) chozas, trampas, armas o actuaciones mágicas, a las simplificaciones de estructuralistas (sobre los cuadrangulares, triangulares, puntiagudos, abiertos vs cerrados... en la dualidad macho/hembra u otra) y a las restricciones de la interpretación chamanista de lo rupestre ${ }^{8}$.

\section{Afirmaciones y dudas}

La comprensión del arte paleolítico no ha superado los protocolos del análisis "preiconográfico» (Sauvet 1993b, 305...); llega justo al reconocimiento del contenido temático primario («los motivos artísticos — los objetos y las acciones- y eventualmente sus combinaciones») pues es "absolutamente inaccesible un análisis iconográfico efectivo... lastrado por prejuicios».

Los textos sobre arte paleolítico (como los de la Etnografía sobre arte/simbología de pueblos primitivos) suponen que unos temas son sólo decoración, mero elemento "geométrico" o abstracto, y que otros se pretenden alusivos a lo real como símbolo más o menos estilizado o esquemático o francamente realista. Según la sugestiva propuesta de G.-H. Luquet (1923, 1926a, 1926b) las imágenes paleolíticas, que intentan retener fielmente la forma del original, lo perciben y expresan desde el realismo, sea directo/visual (lo que se ve, y tal como se ve, en el momento de la actuación

8 El transpuesto en la primera fase de la práctica chamánica (pasando de la plena conciencia precedente a la conciencia alterada en su estado profundo: en estado de trance) percibe «puntos, zigzags, parrillas, conjuntos de líneas rectas o curvadas paralelas» (Clottes y LewisWilliams 2001, 15). 
gráfica) o intelectual/ideal (lo que se se sabe de él y cómo se le recuerda o interpreta) ${ }^{9}$. Así esta visión ideal se enfrenta a la realidad concreta (formal) del modelo, introduciendo en su representación otros «puntos de vista» $\mathrm{y}$ "perspectivas».

\subsection{Lo común y lo alternativo: norma y excepciones}

Hemos pretendido explicar (Bahn 1982; Fortea 1990; Baffier y Girard 2013; Barandiarán M. 2015) correlatos fuertes entre grafemas contemporáneos de muy distante ubicación geográfica: ¿esta ekúmene gráfica es mero efecto de una «mecánica» convergencia cultural o resultado de una autoría compartida producida por la misma mano, en talleres relacionados o por los integrantes de una «escuela»?

Frente a las normas de escuela existen, desde el sudoeste de Europa al centro de Siberia, algunos «independientes» cuyo estilo personal se manifiesta en la descripción de detalles prolijos y en algunos tratamientos muy expresivos: como los grabadores «no conformistas» de La Marche (en la dedicatoria de Pales y Tassin de Saint-Péreuse 1976) y «cuantos en sus creaciones individuales se saltaron los límites establecidos por una amplia tradición» (Müller-Karpe 1982, 203). En el mismo taller o escuela convivían gentes hábiles y mediocres que pese a la necesidad de transmitir los códigos y los gestos que rigen toda expresión gráfica (Fritz 1999, 200) producían resultados gráficos distintos.

\subsection{La figura cabal y su estereotipo: ¿dos versiones de la misma realidad?}

Buena parte de los intentos de comprensión de los grafismos paleolíticos vienen lastrados por los prejuicios, personales o de escuela ${ }^{10}$, de los que creen que en ellos se han de encontrar lo que sus autores percibieron y evocan (en imagen, relato, historia, conmemoración,...) o lo que soñaron y pretendían (en recuerdo, fábula, mito, aplicación mágica, invocación religiosa.... ${ }^{11}$.

Las primeras varillas con decoración curvilínea encontradas en las cuevas pirenaicas de Arudy y de Espalungue/Lourdes eran (Piette 1894) ejemplo del hacer de aquel artista "que no se ciñe a la representación de seres animados e imagina ornamentos cuyo modelo no encuentra en la naturaleza: como la voluta que supo variar en formas más graciosas, sea esculpiendo sus circunvoluciones en relieve, sea incrustándolas a fondo en el asta de reno; o como el círculo cuyo centro sobresale o como los retorcidos en forma de columna».

9 «El arte paleolítico tiene como carácter dominante el realismo... se propone crear imágenes de objetos reales (en particular, de seres vivos [individuales o en "escenas de género»], es decir dar de ellos reproducciones que se les asemejen... pero la semejanza de la imagen con el objeto representado puede ser concebida de modos diferentes"; "el artista no se preocupa por lo que ve, sino por lo que sabe del tema»; se inclina hacia lo cotidiano «reproduciendo, sin intención mágica, un suceso real o imaginado» (Luquet 1926a, 84-90, 116).

10 «Es casi simposible pensar en el hombre prehistórico sin aportar algún juicio de valor, sin hacerlo heredero póstumo de nuestro pensamiento del siglo $\mathrm{xx}$... Muy a menudo nos contentamos con sustituir el pen- samiento de aquél por el del prehistoriador... Según los textos, el hombre prehistórico cambia de personalidad religiosa, sea un mago sanguinario o un piadoso coleccionista de cráneos de antepasados, sea danzante libidinoso o filósofo desengañado según los autores; su comportamiento habría de estudiarse no en función de los datos, que a veces son tan escuetos, endebles y parcos, sino a través de las biografías de los prehistoriadores (Leroi-Gourhan 1971, 2).

11 Así, por ejemplo, el sugerente mitologista F. Bourdier (1968, fig. 111) propone que muchas de las licencias expresivas del grafismo paleolítico que estamos recordando son los «monstruos y quimeras» sońados por aquellas gentes. 
A la contra H. Breuil $(1905,1907)$ explicó las razones por las que lo que inicialmente fuera una figura animal se convertía en motivo ornamental. Opinaba A. Leroi-Gourhan (1965, 43-67) que los autores de imágenes en soportes mobiliares de uso precario utilizaban una doble escritura gráfica, la clásica y la cursiva, coexistiendo las figuras elaboradas con las condensadas, geometrizadas o esquematizadas... hasta llegar a los iconos abstractos «sin referencia aparente con la realidad»; item más (Delluc y Delluc 1990, 52) las figuras de osos identificables y muy esquematizados «atestiguan la doble "escritura» realista y geométrica reunidas sobre un mismo objeto mobiliar» de Raymonden/Chandelade.
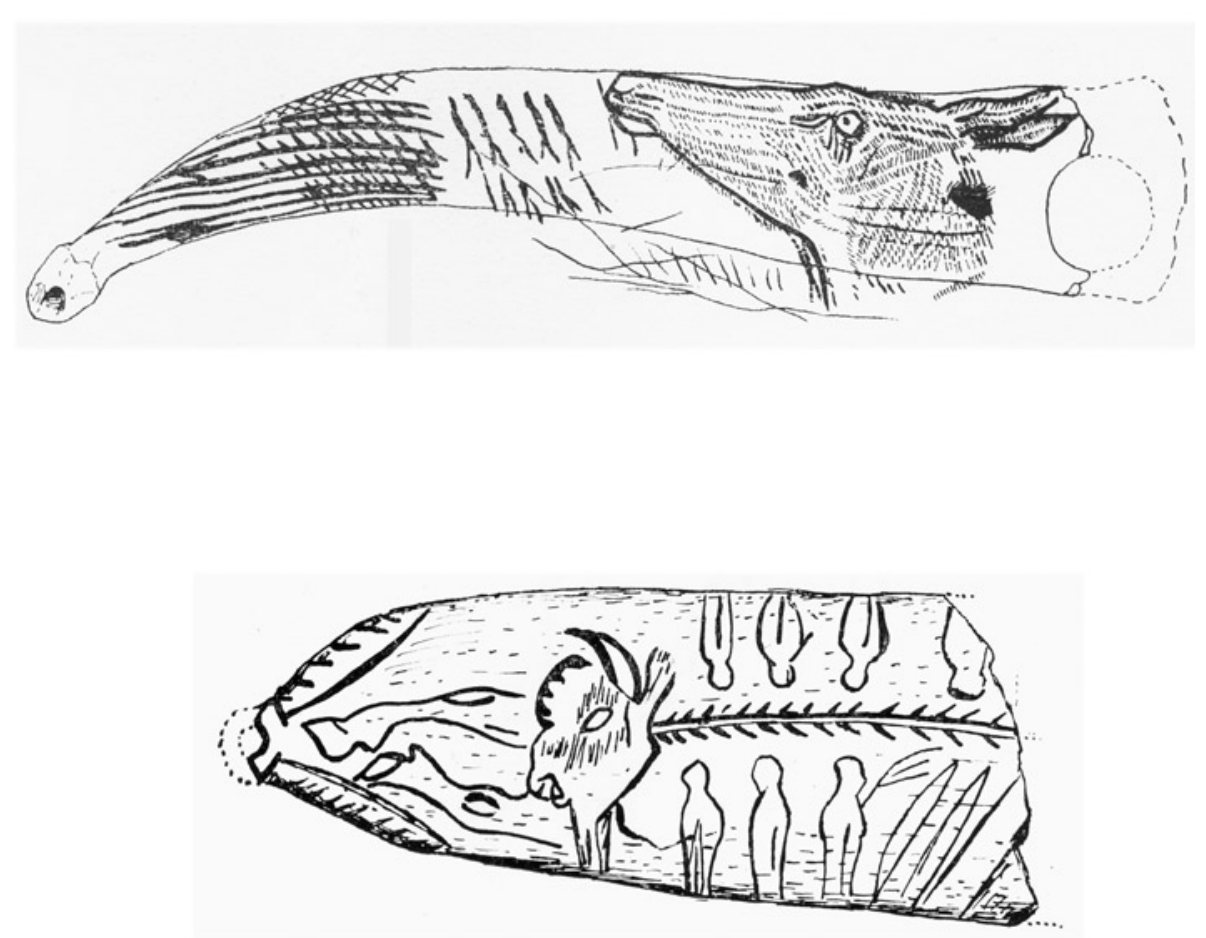

Figura 5. Antropomorfos esquematizados junto a figuras animales realistas en un bastón perforado del Valle y en una bramadera ósea de Raymonden/Chancelade (Obermaier 1932 fig. 4; Marshack 1972 fig. 154)

La idea es compartida, con obvias matizaciones, por cuantos aceptan la inspiración en lo real de los modelos animados del arte paleolítico y, a la vez, su estilización o esquematización, dependiente de la iniciativa de su autor que, en inercia, ahorra detalles ${ }^{12}$. Dos citas de refrendo: i, los «artistas

12 Teniendo en cuenta que «el artista paleolítico parece operar con un esquema, más o menos general, subyacente a las peculiaridades individuales, parece más propio hablar de convencionalismo que de estilización, aunque ésta sea previa a aquélla, lo que, de alguna manera, contribuye a explicar la frecuente coexistencia de representaciones naturalistas con otras estilizadas y aún esquemáticas, en el arte mueble paleolítico» (Corchón y Hoyos 1973.74). En idea de J.D. Guthrie (2005.390392) los tipos «inusuales» de presentación de cabezas, y especialmente las de cabras, serían "formas de experimentación de la creatividad», efecto de una «soltura creativa... hacia formas abstractas». 
cuaternarios (de Lumley 1968, 123 y 126), al fondo de cavernas oscuras y a la luz de antorchas vacilantes, trazaban sobre las paredes perfiles de los grandes mamíferos para los que debían sin duda utilizar algún sistema de construcción cómoda más o menos geométrica...; y quisieron transmitir lo real, con un trazado del dibujo que diera una imagen fiel de la anatomía... pero lo real ha sido voluntaria o inconsciente, pero implacablemente, sometido a formas geométricas, a normas. Instalada una noción todavía confusa de solidaridad entre las formas en la mente del artista, realismo y abstracción parecen haberse combinado en el arte cuaternario»; ii, todas las unidades gráficas (y su acumulación en temas) «transmiten (García-Diez 2001, 116-117) cierta cantidad de información... relativizada por el gusto estético y por otros «intereses» (que desconocemos) adoptados por el artista», considerándolas en gradación «desde la menor concentración y simplificación formal a la mayor donde se reduce todo a simples líneas», lo que inicialmente fuera una "figura» animal.

A lo largo de un siglo largo de bibliografía, es habitual ordenar las fórmulas del imaginario, desde la más real a la más simplificado: p.e. las figuras de peces en «estilo realista», "esquematización» y «estilización» (sendos capítulos III, IV y V de Breuil y Saint-Périer 1927) y el conjunto del bestiario en "naturalista», «esquemático y de perfil estricto» y «estilizado» (Corchón 1986, 153167) o en «realismo», «naturalismo», «expresionismo», «esquematización» y «estilización» (GarcíaDiez 2001, 117).

Entre tantos casos se pueden recordar tres clases de animales (peces de costado, cabras de frente y serpientes) cuyos grafemas los captan tanto en imagen fiel como en versión hipersimplificada y en estadios intermedios de su «evolución».

Son figuras muy detalladas de peces las de salmón (seis individuos en escena con ciervos sobre lo conservado de un bastón de Lortet o el grabado sobre en el Abri du Poisson/Gorge d'Enfer (Piette 1894, 144; Roussot 1984, 155-156), de trucha (grabada sobre el barro del suelo en Niaux: Breuil 1952, fig. 1) y de platija (una como contorno recortado de hueso en Boeufs/Lespugue y dos en grabado parietal de Altxerri: Saint-Périer 1912, 512-514; Altuna y Apellániz 1976, 28-32): en todas se concretan caracteres anatómicos que permiten la determinación razonable de esos taxones. Breuil y Saint-Périer (1927, 11-47) identificaron, además de las habituales figuras de salmónidos (salmones y truchas en versiones parietal y mobiliar), algunos ejemplares, sobre soportes portátiles, de aguas marinas y/o que pueden remontar ríos (el lenguado y el rodaballo entre los pleuronéctidos, la alosa, la caballa y las anguilas) o decididamente continentales (el lucio y, entre varios ciprínidos, el gardí, el escalo y la brema). Cuantificado críticamente ese elenco (CleyetMerle 1987, 399), salvo los salmónidos (39,2\% de la muestra revisada) y efectivos menores de ciprínidos, pleuronéctidos, lucios y anguilas, la mayoría de los peces se representan «de forma sin duda voluntariamente indeterminada» ${ }^{13}$. En su máximo esquema sólo se retienen el contorno de la figura (grafía cerrada y alargada de forma oval, romboide o ahusada) y la línea lateral (trazo longitudinal o algún tipo de mancha que cubre todo el costado) que recorre su cuerpo de cabeza a cola.

13 Aparte de los casos de peces aceptados en los grafismos de la región cantábrica, vale la pena recuperar cuatro del mobiliar del Pendo: una figura en costilla recortada y con grabados llamado "pez esquemático» en su presentación de 1933 y sin ninguna concreción genérica en los catálogos regionales de I. Barandiarán y de S. Corchón (y que Madariaga de la Campa 1969 lo sugiere como Amia calva), sendas figuras grabadas sobre una azagaya y sobre el fragmento proximal de una bramadera que representarían lucios (Corchón 1986, 424) y una lamprea (Madariaga de la Campa 1969, 71) sobre una pieza ósea: Obermaier (1932, 14-16) no se había atrevido a identificar la sugerida Amia calva ni los dos lucios (para él solo se trata de una especie «voraz... y muy probablemente marina»). 
No abundan las versiones más completas de cabras figuradas de frente. Su mejor ejemplo son la grabada/esculpida a lo largo de un propulsor de asta de Mas d'Azil con prolijos detalles de cabeza (cara con su hocico y ojos, orejas y cuernos con sus nudosidades) cuerpo y patas (con pezuñas) y, entre las del repertorio parietal, la algo más sencilla pintada en negro en Niaux (Piette 1905, figs. 60 y 60a; Beltrán et alii 1973, 190-191 y fig. 128).

Más difícil parece trazar cuadros razonables «de evolución» de las figuras de serpientes en el arte mobiliar. Se definieron (Breuil y Saint-Périer 1927, 146-147 y 153) como víboras (de lengua bífida, cabeza triangular ancha y cuerpo algo corto y grueso que se adelgaza bruscamente en su cola $\mathrm{y}$, a veces, detallada su pigmentación dorsal) sendas figuras grabadas sobre una elipse de asta de Lortet («la clave de la serie»), una bramadera de hueso de Rideaux/Lespugue y un cincel de asta de Gourdan. También son aceptables otras imágenes mucho más sintetizadas de reptiles (¡algunas son anguilas?) en grabados mobiliares de Aquitania (Madeleine y Mas d'Azil: Breuil y Saint-Périer 1927, figs. 68.3, 72.3 y 72.5) y de la región cantábrica (Pendo y Valle: Barandiarán M. 1972, fig. 51). Pero ¿deviene (o equivale) al fin todo este imaginario en tantos signos «sinuosos», "zigzags o de línea quebrada» o «serpentiformes» (Barandiarán M. 1972b, 287-289; Chollot 1980, 234242; Corchón 1986, 153-167)?

Las figuras realistas de peces se presentan en parietal y mobiliar; las de cabras y serpientes dominan, con mucho, en soportes muebles. La mayoría de las versiones hipersimplificadas de peces como temas cerrados, de cabezas de cabra de frente como VV embutidas y de serpientes como zigzags $\mathrm{u}$ ondulaciones se ofrecen mayoritariamente sobre utensilios de hueso o de asta de formato alargado.

\subsection{La coexistencia de lo real y lo simplificado}

No funciona la idea de que se excluiría el recurso coincidente (en el mismo trazado argumental y al mismo tiempo) de las figuras «detallistas», «hiperrealistas» o «de precisión fotográfica» y las «hipersimplificadas», «esquematizadas», «condensadas», «degeneradas» o «deformadas». En la proximidad de un mismo soporte mobiliar o de un panel parietal reducido se yuxtaponen, a menudo, tratamientos gráficos en versiones realista y convencional:

- Animales (en realista) y antropomorfos (en convencional) en los grafemas mobiliares de: una cierva, dos caballos y otros temas con tres «diablejos» en un bastón de asta de Mège/Teyjat; un bisonte "trofeo de caza flanqueado por sus (en lo que se conserva) siete muy estilizados captores en una bramadera de Raymonden/Chancelade, un bisonte ante nueve antropomorfos armados en una costilla de Châteu/Les Eyzies y un heterogéneo de animales (caballo, oso, uro y salmón) al que procesionan seis antropomorfos en un tubo de hueso de Vache (Capitan et alii 1909, figs. 4.5 y 11; Capitan et alii 1924, fig. 102; Luquet 1926a, fig. 113 abajo; Nougier y Robert 1968, 17-29).

—Unas especies animales y otras: sobre el tubo óseo de Valle (Breuil y Obermaier 1912, 5-6) figuran dos caballos realistas, un ciervo estilizado de frente, siete óvalos rellenos con líneas oblícuas (¿esquemas de peces?) y algún difícil signo.

- Unos individuos y otros de la misma especie: como las cabras realistas de frente o de costado y las simplificadas en visión frontal en $\mathrm{V}$ compartiendo el mismo soporte mueble: el colgante sobre hueso largo de Mas d'Azil con tres cabezas dibujadas con toda fidelidad sobre una cara del soporte y muy distorsionada la figura completa sobre la otra (Pales y Tassin de Saint-Péreuse 1981,129 ) o un trozo de costilla de Llonín y un bloque de piedra de Abauntz (Fortea 
et alii 2004; Utrilla et alii 2007) donde coinciden figuras más realistas (de costado o de frente) con otras muy esquematizadas (de frente). En una varilla de asta de Raymonden/Chancelade se grabaron cabezas de oso: dos «bien reconocibles» y varias «en X... muy esquematizadas y geometrizadas, que resultarían casi ininteligibles si no fuera por la presencia contigua de los modelos realistas" (Delluc y Delluc 1990, 52).

—Unas partes y otras del mismo individuo: el bisonte simplificado (¿grotesco?) que pierde por la herida de su zona inguinal un muy verista paquete de su colon espiral en la escena pintada del pozo de Lascaux o los pares de patas extremadamente esquematizadas trazadas junto al pecho de las detalladísimas cabeza+cuello de ciervo, caballo, rebeco y bovino grabados sobre un cúbito de Torre (Bouchud 1966, 36; Barandiarán M. 1971).

En las imágenes de caballos y de renos frecuentemente se adjuntan al realismo del conjunto de sus cuerpos (fiel en su referencia de taxones concretos, 'hasta razas?) convenciones para referir detalles (p.e. de pelaje) que nos cuesta explicar. Paleozoólogos y arqueólogos han identificado en el bestiario paleolítico concretas variantes morfotaxonómicas de los géneros Equus ${ }^{14}$ y Rangifer ${ }^{15}$. En el efectivo de 116 figuras de caballos grabados en Combarelles se distinguieron (Capitan et alii 1929, 169-183) los tipos líbico, céltico, tarpán, nórdico y acaso algún Przewalski y en el de sus 13 de renos (ibid., 146-147) sus variantes de tundra y de bosque. Se han aceptado (Piveteau 1957 retomando observaciones de Bourdelle 1938) como imágenes de caballos longilíneos de tipo tarpán algunos de Font-de-Gaume, Portel y Lascaux, brevilíneos de tipo céltico otros de Font-de-Gaume y de tipo poney algunos de Lascaux; son distintos los formatos de los caballos completos de Ekain (Lión 1971, 78): 7 longilíneos, 2 brevilíneos y 1 mediolíneo. Se asegura (Bouchud 1966, 13-21) que así como en el parietal de Font-de-Gaume se representaron renos de tundra, en la amplia serie de placas de Limeuil aparecen tanto las variantes de tundra (R.t. caribou y R.t. arcticus) como la de bosque $(R$. terranovae).

Figuras tan bien definidas por su realismo en el delineado general de su silueta son acompañadas por convenciones concentradas en los flancos. En los caballos son tantas clases de despieces (Barandiarán M. 1972a, 358-366): parietal en Le Portel, Rouffignac, Combarelles, Lascaux, Ekain, Hornos de la Peña, Monedas ... y mobiliar en Espelugues/Lourdes, Montastruc/Bruniquel, Mège, Lumentxa,... Y en renos varias delineaciones longitudinales (ibid., 366-369): en línea continua y alineaciones de puntos y manchones (parietal en Altxerri o Trois-Frères, mobiliar en Colombière, Kesslerloch, Limeuil Montastruc/Bruniquel, Vache, Morin...), en zigzag (parietal en Altxerri o Trois-Frères, mobiliar en Isturitz, Limeuil o Madeleine) y en banda de líneas oblicuas (mobiliar en Mairie/Teyjat).

\subsection{Lo convencional como marcador cultural}

Algunas convenciones del imaginario (en cánones, esquemas, estilización etc.) son comunes a muchos grupos de obra (familias documentales) en concretos lapsos temporales y territorios. Entre estos fósiles característicos o marcadores culturales:

14 Son (Bourdelle 1938, Piveteau 1957 y Lión 1971) de formato longilíneo o brevilíneo y de tipo nórdico, céltico, poney, tarpán etc... descartados, por mal definidos, los que en alguna bibliografía se han adjetivado como «de cabeza de pato», «cebrados»...
15 Las dos variantes del reno (Bouchud 1966), distinguidas en figuras paleolíticas por la forma de sus astas (cylindricornis o más masivas y compressicornis o aplanadas), se corresponden respectivamente con los actuales renos "de tundra" (Rangifer tarandus, R.t.arcticus y R.t. caribou) y «de bosque» (R. terranovae). 
— las estatuillas animales en marfil (de formas muy sintetizadas y dotadas de convenciones en aspa, puntuaciones) del círculo auriñaciense antiguo de Suabia (Vogelherd, Geissenklösterle, Hohlenstein...) (Albrecht et alii 1989);

- las figuras de vulvas grabadas en bloques de piedra del Auriñaciense típico y Gravetiense de Dordoña (Blanchard, Ferrassie, Castanet, du Poisson, Cellier etc.) (Delluc y Delluc 1978);
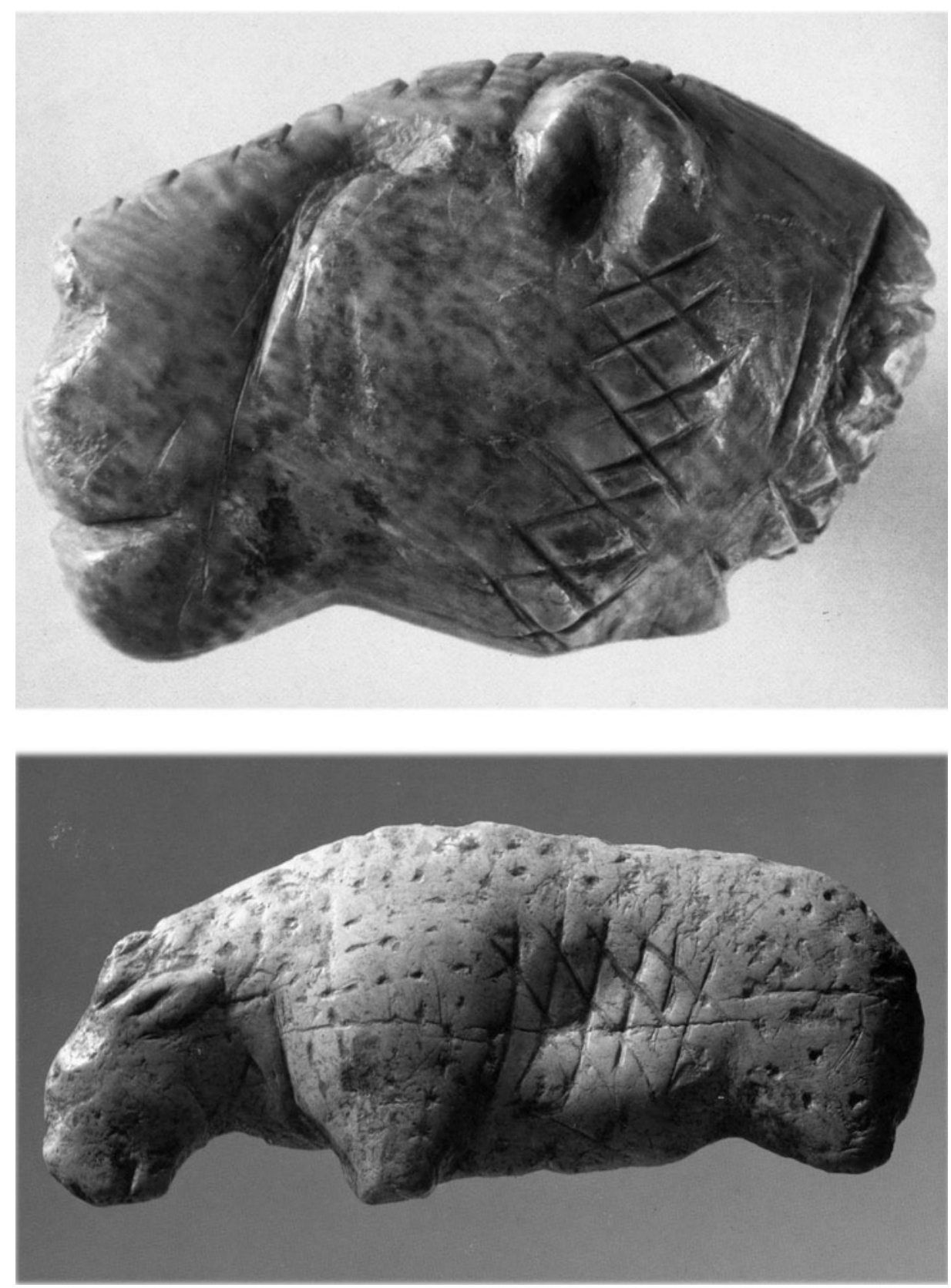

Figura 6. Leones (cabeza y completo) de Vogelherd esculpidos en marfil y con trazos geométricos grabados (Albrecht et alii 1989 láms. 3a y 5b) 
—las estatuillas femeninas en marfil del Paleolítico superior antiguo siberiano (Malta y Buret) con cabeza grande (y pelo adornado), cuerpo muy simple, brazos bajo los pechos, etc. (Abramova 1990);

— las figuras de caballos de hocico aplastado y afilado («en pico de pato») asignados el Gravetiense en manifestaciones parietales del sudoeste de Europa, desde el sur de la Península (cueva de Ardales) hasta el centro de Francia (en Dordońa y algo más al norte) (Sauvet et alii 2013, 353-354);

- el trazado estriado acumulado en planos de la parte anterior de ciervas (y algún otro animal) grabados en mobiliar y en rupestre del Magdaleniense inferior de la franja septentrional de Iberia (Altamira, Castillo y otros casos) (Alonso Silió 1988; González Sáinz 1992);

— las siluetas femeninas simplificadas de «tipo Gönnerdorf» en bastantes grabados mobiliares y parietales (Bosinski y Schiller 1998; Bosinski et alii 2001);

- las cabras en posición frontal («en alerta») en versión muy esquematizada propia del arte mueble y parietal del Magdaleniense medio a final en el espacio cántabro-aquitano (Sauvet et alii 2008; Barandiarán M. et alii 2013);

- los caballos de cabeza hipertrofiada (Apellániz 1990) grabados sobre soportes de asta del Magdaleniense avanzado de sitios de Dordońa y aledaños (Madeleine, Morin, Souci...);

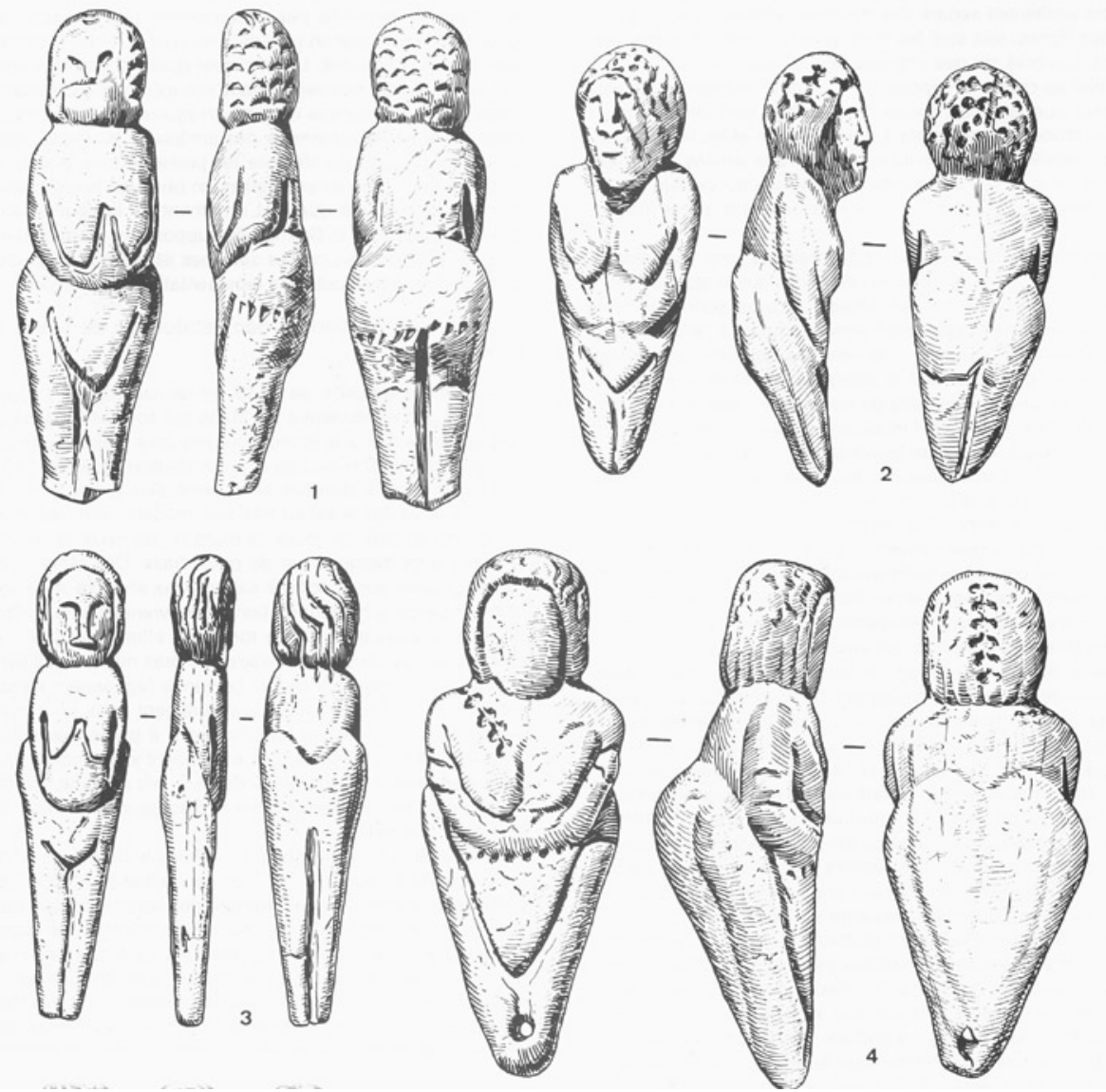

Figura 7. Modelos de venus siberianas tipo Malta (Abramova 1990 fig. 2) 
- o las figuras aisladas con tracitos y entrecruzados muy juntos que delinean contornos o rellenan sus cuerpos con bandas periféricas de sus cuerpos del Magdaleniense terminal e inmediato Epipaleolítico (sobre huesos de Borie-del-Rey y Pont-d'Ambon, correspondientes al estilo V«de» A. Leroi-Gourhan) (Roussot 1990).

\section{BibliografíA}

Abramova, Z. A., 1967, «Palaeolithic Art in the U.S.S.R.», Arctic Anthropology IV.2, 1-179.

—, 1990, «Bases objectives de la chronologie de l'art mobilier paléolithique en Sibérie», L'Art des objets au Paléolithique. Tome 1. L'art mobilier et son contexte, 143-153, Paris: Ministère de la Culture et alii.

Aвsolon, K., 1949, «The diluvial anthropomorphic statuettes and drawings, especially the so-called Venus statuettes discovered in Moravia», Artibus Asiae 12.3, 201-220.

Albrecht, G., Bosinski, G., Feustel, R., Hahn, J., Klíma, B., Müller-Beck, H., 1989, Los comienzos del Arte en Europa Central, Madrid: Museo Arqueológico Nacional.

Alcalde del Río, H., Breuil, H., Sierra, L., 1911, Les Cavernes de la Région Cantabrique (Espagne), Peintures et gravures murales des cavernes paléolithiques, Monaco: A. Chène.

Alonso Silió, R., 1986, «El modelado interior de los grabados rupestres paleolíticos del Norte de la Península», Estudios de Arte Paleolitico, 133-264, Madrid: Centro de Investigación y Museo de Altamira Monografía n. ${ }^{\circ} 15$.

Altuna, J., Apellániz, J.M., 1978, Las figuras rupestres paleoliticas de la cueva de Ekain (Deva, Guipuizcoa), Munibe 30.

Apellániz, J.M., 1990, "Modèle d'analyse d'une école dans l'iconographie mobilier paléolithique: l'école des graveurs de chevaux hypertrophiés de La Madeleine», L'Art des objets au Paléolithique. Tome 2. Les voies de la recherche, 105-138, Paris: Ministère de la Culture et alii.

Aranzadi, T. de, Barandiarán, J.M. De, Eguren, E. DE, 1926, Exploraciones de la caverna de Santimamiñe (Basondo: Cortézubi). 1a memoria. Figuras rupestres, Bilbao: Diputación de Vizcaya.

Azéma, M., 2010, L'Art des cavernes en action. Tome 2: Les animaux figurés. Animation et mouvement, l'illusion de la vie, Paris: Errance.

Baffier, D., Girard, M,. 2013, «Identification d'un artiste, d'un groupe ethnique, d'une culture? Exemple de la Frise Rouge de la Grande Grotte d'Arcy-sur-Cure (Yonne)», F. Javier Fortea Pérez, Universitatis Ovetensis Magister. Estudios en homenaje, 415-427, Oviedo: Gobierno del Principado de Asturias y Mensula.

Bahn, P.G., 1982, «Inter-site and inter-regional links during the Upper Palaeolithic: the Pyrenean evidence», Oxford Journal of Archaeology I.3, 247-268.

Bahn, P.G., Vertut, J., 1988, Images of the Ice Age, Leicester; Windward.

Barandiarán A(Yerbe), J.M. DE, 1950, «Bolinkoba y otros yacimientos paleolíticos en la sierra de Amboto", Cuadernos de Historia Primitiva V.2, 73-112.

—, 1964, «La cueva de Altxerri y sus figuras rupestres», Munibe 16, 91-141.

Barandiarán M(aestu), I., 1971, «Hueso con grabados paleolíticos en Torre (Oyarzun, Guipúzcoa)», Munibe 23, 37-70.

—, 1972a, "Algunas convenciones de representación en las figuras animales del arte paleolítico», Santander Symposium. Symposium Internacional de Arte Rupestre, 345-381, Santander/Madrid: U.I.S.P.P. y C.S.I.C.

—, 1972b, Arte mueble del Paleolítico cantábrico, Monografías Arqueológicas 3, Zaragoza: Universidad.

—, 1974, «Representaciones de caballos en la cueva de Ekain», Estudios de Arqueología Alavesa 6, 47-56.

—, 1984a, «Signos asociados a hocicos de animales en el arte paleolítico», Veleia 1, 7-24.

—, 1984b, "Utilización del espacio y proceso gráfico en el arte mueble paleolítico», Scripta Praehistorica F.Jorda oblata. Acta Salmanticensia, 113-161. 
—, 2006, Imágenes y adornos en el arte portátil paleolitico, Barcelona: Ariel Prehistoria.

—, 2015, «Contextualización arqueológica de La Covaciella. Una koiné pirenaico-cantábrica en el Magdaleniense medio» en: M. García-Diez et alii, Arte rupestre paleolitico en la cueva de La Covaciella (Inguanzo, Asturias), 125-144. EAA Monografías 3, Oviedo: Gobierno del Principado de Asturias.

Barandiarán M., I., Cava, A., Gundín, E., 2013, "La cabra alerta: marcador gráfico del Magdaleniense cantábrico avanzado", en: J. Fortea Pérez. Universitatis Ovetensis Magister. Estudios en homenaje, 263286, Oviedo: Gobierno del Principado de Asturias y Mensula.

Barandiarán M., I., Laplace, G., 2000, «Temas, espacio decorativo y composición: dos compresores magdalenienses de Poeymaü (Pyrénées Atlantiques)», Saldvie. Estudios de Prehistoria y Arqueología 1, 7-34.

BARrière, C., 1970, «Les techniques de la gravure à Rouffignac», Travaux de l'Institut d'art préhistorique de Toulouse 12, 11-153.

Beltrán, A., Gailli, R., Robert, R., 1973, La cueva de Niaux, Monografías Arqueológicas 16, Zaragoza: Universidad.

Bosinski, G., D’Errico, F., Schiller, P., 2001, Die gravierten Frauendarstellungen von Gönnersdorf. Wiesbaden: Der Magdalénien-Fundplatz Gönnersdorf band 8.

Bosinski, G., Schiller, P., 1998, «Représentations féminines dans la Grotte du Planchard (VallonPont-d'Arc, Ardèche) et les figures du type Gönnersdorf dans l'art pariétal», Préhistoire Ariègeoise 52, 99-140.

Bouchud, J., 1966, Essai sur le renne et la climatologie du Paléolithique moyen et supérieur, Périgueux: Magne.

Bourdelle, E., 1938, Essai d'une étude morphologique des équidés préhistoriques de France d'après les gravures rupestres, Paris: Mammalia II.

Bourdier, F., 1967, Préhistoire de France, Paris: Flammarion.

Breuil, H., 1905, «La dégénérescence de figures d'animaux en motifs ornamentaux à leépoque du Renne», Comptes rendus de l'Académie des Inscriptions et Belles Lettres, Paris.

—, 1907, «Exemples de figures dégénérées et stylisées à l'époque du Renne», XIII Congrès International d'Anthropologie et d'Archéologie préhistoriques. Monaco, 394-403.

—, 1952, «La caverne de Niaux. Complements inédits sur sa decoration», Bulletin de la Société Préhistorique de l'Ariège 7, 11-35.

—, 1963, «Théories et faits cantabriques relatifs au Paléolihique supérieur et à son art», en: A Pedro Bosch Gimpera en el septuagésimo aniversario de su nacimiento, 53-57, México: Instituto Nacional de Antropología e Historia.

Breuil, H., Lantier, R., 1959, Les hommes de la pierre ancienne (Paléolithique et Mésolithique) (2. èd.), Paris: Payot.

Breuil, H.; Obermaier, H., 1912, «Les premiers travaux de l'Institut de Paléontologie Humaine», L'Anthropologie 23.

—, 1913, «Institut de Paléontologie Humaine. Travaux exécutés en 1912», L'Anthropologie, 24, 1-16.

Breuil, H., SAInt-PÉRIer, R. DE, 1927, Les poissons, les batraciens et les reptiles dans l'art quaternaire. Archives de l'Institut de Paléontologie Humaine, mem. 2, Paris: Masson.

Capitan, L., Breuil, H., Bourrinet, M., Peyrony, D., 1909, "Observations sur un bâton de commandement orné de figures animales et de personnages semi-humains», Revue mensuelle de l'Ecole d'Anthropologie de Paris 19e année.

Capitan, L., Breuil, H., Peyrony, D., 1910, La Caverne de Font-de-Gaume aux Eyzies (Dordogne), Peintures et gravures murales des cavernes paléolithiques, Monaco: Chène.

—, 1924, Les Combarelles aux Eyzies (Dordogne), Institut de Paléontologie Humaine, Peintures et gravures murales des cavernes paléolithiques, Paris: Masson.

Capitan, L.; Peyrony, D., 1928, La Madeleine, Son gisement, son industrie, ses oeuvres d'art, Paris: Publications de l'Institut International d'Anthropologie n. ${ }^{\circ} 2$.

Casado, M.P., 1977, Los signos en el arte paleolitico de la Península Ibérica. Monografías Arqueológicas 20, Zaragoza: Universidad. 
Chauvet, G., 1919, Grotte du Chaffaud. L'art primitif. Quelques poitevins d'avant l'histoire. Mémoires des Antiquaires de l'Ouest X, Poitiers.

Сноllot, M., 1980, Les origines du graphisme symbolique. Essai d'analyse des écritures primitives en Préhistoire, Paris: Fondation Singer-Polignac.

Cleyet-Merle, J.-J., 1987, "Les figurations de poissons dans l'art paléolithique», Bulletin de la Société Préhistorique Française, 84, 394-402.

Clottes, J., 1987, «La determinación de las representaciones humanas y animales en el arte paleolítico europeo", I Congreso Internacional de Arte Rupestre. Bajo Aragón Prehistoria 8/9, 41-68.

Clottes, J., Lewis-Williams, D., 2001, Los chamanes de la Prehistoria, Barcelona: Ariel Prehistoria.

Corchón, M.S., 1986, El arte mueble paleolítico cantábrico: contexto y análisis interno. Centro de Investigación y Museo de Altamira, Monografía n. ${ }^{\circ}$ 16, Madrid: Ministerio de Cultura.

Corchón, M.S., Hoyos, M., 1973, "La cueva de Sofoxó (Las Regueras, Asturias)», Zephyrus 23/24, 39100.

Delluc, B., Delluc, G., 1978, «Les manifestations graphiques aurignaciens sur support rocheux des environs des Eyzies (Dordogne)», Gallia Préhistoire 21, 213-438.

—, 1990, "Le décor des objets utilitaires du Paléolithique supérieur», L'art des objets au Paléolithique. Tome 2. Les voies de la recherche, 40-72, Paris: Ministère de la Culture.

Duhard, J.-P., 1996, Réalisme de l'image masculine paléolithique, Grenoble: Jérôme Millon.

Fortea, J., 1990, «Abrigo de La Viña. Informe de las campañas 1980-1986», Excavaciones arqueológicas en Asturias 1983-86, 55-68. Oviedo: Principado de Asturias.

Fortea, J., Rasilla, M. De la, Rodríguez, V., 2004, «L'art pariétal et la séquence archéologique de la grotte du Llonín (Peñamellera Alta, Asturies, Espagne)», Préhistoire, Art et Societés 54, 7-29.

Fritz, C., 1998, «Sociétés magdaléniennes et techniques de gravure sur os», Art et Société dans le Magdalénien pyrénéen, rapport triennal 1996-98, 109-119, Toulouse: Projet Collectif de Recherche.

-, 1999, La gravure dans l'art mobilier magdalénien. Du geste à la représentation. Contribution de l'analyse microscopique, Documents d'archéologie française 75, Paris.

García-Diez, M., 2001, Comportamiento gráfico durante el Paleolítico superior en el Alto Asón: análisis de los dispositivos iconográficos rupestres, Tesis Doctoral, Vitoria: Universidad del País Vasco.

García Guinea, M.A., 1986, Los bastones magdalenienses en Cantabria. El hallazgo de Cualventi (Oreña), Santander: UNED de Cantabria.

GonzÁlez SÁInZ, C., 1992, "Algunos paralelos entre el arte mobiliar y el rupestre. Una revisión crítica», en: Repensar Altamira, Santander: Curso de la Universidad Internacional Menéndez y Pelayo.

GonzÁlez-Pumariega, M., 2013, «La figura de pez de la Cueva del Pindal (Asturias). Un salmón disfrazado de atún», en: J. Fortea Pérez. Universitatis Ovetensis Magister. Estudios en homenaje, 363-373, Oviedo: Gobierno del Principado de Asturias y Mensula.

Graziosi, P., 1956, L'Arte dell'Antica Età della Pietra, Firenze: Sansoni.

Groenen, M., 2000, Sombra y luz en el arte paleolitico, Barcelona: Ariel Prehistoria.

Guthrie, J.D., 2005, The Nature of Paleolithic Art, Chicago/London: The University of Chicago Press.

Haensch, W. G., 1968, Die paläolithischen Menschendarstellungen aus der sicht der somatischen Anthropologie. Menschenbildnisse auf Gravierungen, Reliefs und Malereien in Südwestfrankreich und Nordostspanien, Antiquitas 2 band 8, Bonn: Rudolf Habelt.

JordÁ, F., 1964, «Sobre técnicas, temas y etapas del arte paleolítico en la región cantábrica», Zephyrus 15, $5-25$.

Lantier, R., 1961, La vie préhistorique (4è éd.), Paris, Presses Universitaires de France.

Leonardi, P., 1989, Sacralità, arte e grafia paleolitiche. Splendori e problemi. Calliano: Manfrini.

Leroi-Gourhan, A., 1958a, "La fonction des signes dans les sanctuaires paléolithiques», Bulletin de la Societé Préhistorique Française 55, 307-321.

—, 1958b, «Le symbolisms des grandes signes dans l'art pariétal paléolithique», Bulletin de la Societé Préhistorique Française 55, 384-398.

—, 1965, Préhistoire de l'Art Occidental, Paris: Lucien Mazenod. 
—, 1971, Les religions de la Préhistoire (Paléolithique), Paris, Presses Universitaires de France.

—, 1975, "Préhistoire», Annuaire du Collège de France 1974-1975. 75 e année Résumé des Cours 1974-1975.

Lión, R., 1971, El caballo en el arte cántabro-aquitano, Estudio estilístico, hipométrico y faneróptico de las representaciones paleoliticas, Publicaciones del Patronato de las cuevas prehistóricas de la provincia de Santander VIII.

Lомво, A., 2014, «Interpretación de retruécanos, imágenes de doble sentido y bromas en el arte paleolítico", Complutum 25.1, 35-46.

—, 2015, "Grotescos, máscaras y "fantômes» en el arte paleolítico. Análisis conceptual y revisión crítica», Pyrenae 46.2, 7-29.

Lombo, A., Hernando, C., Martínez Bea, M., 2014, «Mirando atrás. Las representaciones de zoomorfos retrospicientes en el arte paleolítico europeo», Munibe, Antropologia-Arkeologia 65, 37-51.

Lumley, H. DE, 1968, «Proportions et constructions dans l'art paléolithique: le bison», Simposio Internacional de Arte Rupestre, 123-145, Barcelona: Instituto de Prehistoria y Arqueología.

LuQuet, G.-H., 1923, «Le réalisme dans l'art paléolithique», L'Anthropologie 33, 17-48.

—, 1926a, L'art et la religion des hommes fossiles, Paris: Masson.

—, 1926b, "Les origines de l'art figuré», Jahrbuch für Prähistorische und Ethnographische Kunst, 1926, 3-28.

Madariaga de la CAMPa, B., 1969, Las pinturas rupestres de animales en la región franco-cantábrica. Notas para su estudio e identificación, Santander: Instituto de Prehistoria y Arqueología Sautuola.

Marshack, A., 1972, The Roots of Civilisation. The cognitive beginnings of man's first art, symbol and notation, London: Weidenfeld and Nicholson.

MazÁk, V., 1961, «Haarweschel und Haarwuchs des Przewalski-Pferdes, Equus przewalskii Poliakov 1881, und Onager, Equus hemionus onager Boddaert 1785, im Prager zoologischen garten», Equus, 141-163.

Mingo, A., 2010, Los signos rupestres del Paleolitico: la cueva de El Castillo (Puente Viesgo, Cantabria), Santander: Geo Patrimonio/Gobierno de Cantabria.

Mons, L., 1990, «Les figures incomplètes dans l'art paléolithique; leurs particularismos techniques et graphiques», L'art des objets au Paléolithique. Tome 2: Les voies de la recherche, 73-77, Paris: Ministère de la Culture et al.

Mortillet, G. De, Mortillet, A. De, 1881, Musée Préhistorique, album de 100 planches, Paris: C. Reinwald.

Müller-Karpe, H., 1982, Historia de la Edad de Piedra, Madrid: Gredos.

Nougier, L.R., Robert, R., 1968, «Scène d'initiation de la grotte de La Vache, à Alliat (Ariège). I. Étude de la gravure sur os de la Vache», Bulletin de la Société Préhistorique de l'Ariège 23, 13-31.

Obermaier, H., 1916, El Hombre fósil, Memoria 9 de la Comisión de Investigaciones Paleontológicas y Prehistóricas, Madrid.

—, 1932, "Oeuvres d'art du Magdalénien final de la grotte du "Pendo", près Santander (Espagne), Préhistoire I.1, 9-18.

Oтte, M., 1997, "Constitution d'une grammaire plastique préhistorique», L'Anthropologie 101, 5-23.

Pales, L., Tassin de Saint Péreuse, M., 1976, Les gravures de La Marche. II. Les Humains, Paris: Ophrys.

—, 1981, Les gravures de La Marche. III. Equidés et Bovidés, Paris: Ophrys.

Passemard, E., 1944, La Caverne d'Isturitz en Pays Basque, Préhistoire IX, Paris.

Piette, E., 1894, «Notes pour servir à l'histoire de l'art primitif», L'Anthropologie 5, 129-146.

—, 1905, «Études d'ethnographie préhistorique. VII, Classification des sédiments formés dans les Cavernes de l'âge du Renne», L'Anthropologie 15, 129-177.

Piveteau, J., 1958, «Représentations de Périssodactyles dans l'art du Paléolihique supérieur», Traité de Paléontologie VI.2, 493-497, Paris: Masson.

Reinach, S., 1913, Répertoire de l'art quaternaire, Paris: Ernest Leroux.

Ripoll, E., 1972, La Cueva de las Monedas en Puente Viesgo (Santander), Monografías de Arte Rupestre, Arte Paleolítico n. ${ }^{\circ}$ 1, Barcelona: Instituto de Prehistoria y Arqueología.

—, 1964, "Problemas cronológicos del arte paleolítico», Prehistoric Art of the Western Mediterranean and the Sahara, 83-100, Chicago: Viking Fund Publications in Anthropology. 
Robert, E, 2006, Les signes et leurs supports pariétaux. Anlyse comparée des rapports entre les representation abstraites et les reliefs naturels dans les grottes ornées du Paléolithique supérieur au sein de l'espace franco-cantabrique, Thèse de Doctorât, Paris: Université de Paris 1, Panthéon-Sorbonne.

Roussot, A., 1984, "Abri du Poisson", L'art des cavernes. Atlas des grottes ornées paléolithiques françaises, 154-156, Atlas archéologiques de la France, Paris: Ministère de la Culture.

—, 1990, "Art mobilier et pariétal du Périgord et de la Gironde: comparaisons stylistiques», L'art des objets au Paléolithique. Tome 1. L'art mobilier et son contexte, 189-202, Paris: Ministère de la Culture.

SAINT-PÉRIER, R. DE, 1929, «Les baguettes sculptées dans l'art paléolithique», L'Anthropologie 39, 43-64.

—, 1936, La grotte d'Isturitz. II. Le Magdalénien de la Grande Salle. Archives de l'Institut de Paléontologie Humaine mémoire 17, Paris: Masson.

Sauvet, G., 1990, «Les signes dans l'art mobilier», L'art des objets au Paléolithique. Tome 2: Les voies de la recherche, 83-98, Paris: Ministère de la Culture et alii.

—, 1993a, "Les signes pariétaux», L'art pariétal paléolithique. Techniques et méthodes d'étude, 219-234, Paris: Ministère de l'Enseignement Supérieur et de la Recherche.

—, 1993b, «La technique et la forme. 3. La composition de l'espace orné», L'art pariétal paléolithique. Techniques et méthodes d'étude, 297-309, Paris: Ministère de l'Enseignement Supérieur et de la Recherche.

Sauvet, G., Fortea, J., Fritz, C., Tosello, G., 2008, «Crónica de los intercambios paleolíticos: la contribución del arte para el periodo 20000-12000 años BP», Zephyrus 61, 35-59.

Sauvet, G., Fritz, C., Tosello, G., 2013, «El arte paleolítico antiguo del norte de España en su contexto europeo", J. Fortea Pérez. Universitatis Ovetensis Magister. Estudios en homenaje, 347-362, Oviedo: Gobierno del Principado de Asturias y Mensula.

Sauvet, G., Sauvet, S., WlodarczyK, A., 1979, "Essai de sémiologie préhistorique (pour une théorie des premiers signes graphiques) ", Bulletin de la Societé Préhistorique Française, 74, 545-558.

Schmidt, E., 1964, «Remarques au sujet d'une representation de Bouquetin à Niaux», Bulletin de la Société Préhistorique de l'Ariège 19, 33-39.

Sievering, A. 1972, «Art mobilier in Britain», Santander Symposium. Symposium Internacional de Arte Rupestre, 385-386, Santander/Madrid: U.I.S.P.P. y C.S.I.C.

Sievering, A., 1987, A Catalogue of Palaeolithic Art in the British Museum, London: British Museum Publications.

Tosello, G., 2003, Pierres gravées du Périgord magdalénien. Art, symboles, territoires. XXXVIè supplément à Gallia Préhistoire, Paris.

Twiesselmann, F., 1951, Les représentations de l'homme et des animaux quaternaires découvertes en Belgique. Revision des documents déja connus et description de documents inédits, Memoire 113 de l'Institut royal des Sciences Naturelles de Belgique, Bruxelles.

Utrilla, P., Mazo, C., Sopena, M.C., Domingo, R., Martínez Bea, M., 2007, «Ríos, montañas y charcas: una representación de paisaje en el bloque 1 de la cueva de Abauntz», Homenaje a Ignacio Barandiarán Maestu, Veleia 24-25, 229-260.

Zervos, Ch., 1959, L'art de l'époque du renne en France, Paris: Cahiers d'art. 